\title{
A journey of learning organization in social science: interview with Silvia Gherardi
}

\begin{abstract}
Purpose - This paper aims to attempt to provide an overview of the valuable scientific contribution on learning organization in social science from the perspectives of Professor Silvia Gherardi and discusses the evolution of Silvia's work over her long career.

Design/methodology/approach - With the collaboration of this leading scholar, Professor Silvia Gherardi, this paper investigates several topics pertaining to the debate on Learning Organization and provides a unique perspective on the development of these theories.

Findings - Starting from the Italian perspective, in which knowledge and learning are mainly social and cultural phenomena, the paper focuses on Professor Silvia Gherardi's contribution to the emerging area of practice-based theorizing of knowing and learning in organizations.

Originality/value - In the light of different epistemological approaches and views, the discussion with Professor Silvia Gherardi reveals her practice-based perspective. She proposes a historical analysis of the evolution of the Learning Organization debate, thus providing fertile ground for both researchers and practitioners.
\end{abstract}

Keywords Learning organizations, Interview, Knowing in practice, Knowledge in action, Practice based studies, Social approaches

Paper type General review

\section{Introduction}

This article continues the series of interviews pertaining to learning organization which aim to investigate various perspectives of learning organization definitions and concepts by taking advantage of both theoretical findings and the current thoughts of those who have realistically developed these theories.

As proved in various publications, learning organization definitions and concepts are not always consistent, as they are based on different epistemologies and theoretical backgrounds, or refer to various practical approaches and experiences. This interview sheds light on how social practice has influenced the concepts of learning organization in both early development and later applications. In particular, this article delves into understanding the definition of the learning organization from the perspective of Professor Silvia Gherardi who has been at the forefront of defining learning organization for over four decades. It summarizes Gherardi's prolific research and teaching activities and her perspective of post-humanist practice theory.

(C) Roberta Cuel. Published by Emerald Publishing Limited. This article is published under the Creative Commons Attribution (CC BY 4.0) licence. Anyone may reproduce, distribute, translate and create derivative works of this article (for both commercial and non-commercial purposes), subject to full attribution to the original publication and authors. The full terms of this licence may be seen at http://creativecommons.org/licences/by/4.0/legalcode 
TLO

27,5

The interview questions follow the same protocol as the previous article in the series (Sidani and Reese, 2018a, 2018b; Reese, 2020). The questions explore Gherardi's point of view on the learning organization theory as well as where the practice lens is used to better understand both her early contributions and the more recent theoretical findings.

Professor Gherardi is a former senior sociology academic in work and organization in the Department of Sociology, University of Trento, Italy, where she had been Director of the Research Unit on Communication, Organizational Learning and Aesthetics (www.unitn.it/ rucola) since 1993. She has published more than 100 papers, actively contributing to top scientific journals such as Organization, Management Learning and Human Relations. In her long career, she has written around 35 books (collective or as single author) and continues to contribute to a relevant number of chapters and publications in the field of social practices, organization studies and organizational learning. According to Google Scholar, she has received 21,330 citations and an H index of 59.

Gherardi is considered one of the most influential researchers in the field of organization studies. She has worked as a Professor at the Oslo Institute of Educational Research (20132017), the Malardalen University, Sweden (2019-2022), as visiting professor in the Macquarie University, Sydney (June, 2018) and Aalto University, School of Business (20142016). Gherardi has received various awards and honours; the most important are the three Doctor Honoris Causa received from the Department of Social Sciences, Danish Roskilde University (2005), University of Kuopio (East Finland University) in 2010, and from St Andrews University, Scotland (2014). In 2007, she was also nominated Honorary Member of the European Group of Organizational Studies.

Some of her most important and cited contributions in the field of practice studies are: the book published in 2006 entitled Organizational knowledge: The texture of workplace learning with more than 1,300 citations (Gherardi, 2006), the article in Organization entitled Practicebased theorizing on learning and knowing in organizations (Gherardi, 2000) with more than 1,114 citations, and the paper Introduction: The Critical Power of the Practice Lens (Gherardi, 2009) with more than 530 citations. The evolution of Gherardi's work is also revealed and crystalized in the two following books: a first version in Italian entitled Studiare le pratiche lavorative (Bruni and Gherardi, 2007) and the second version titled How to conduct a practicebased study: problems and methods first (Gherardi, 2012), and second edition (Gherardi, 2019). In these contributions, how social practices and practice-based approaches has influenced organizational learning over time clearly emerges. During the 1980s and 1990s, contrasting an objectivist and normative approach on organizational learning did exist and later became an integral part of the theory. This evolution will be explained in the following sections.

\section{How do you define the learning organization?}

When asked about her definition of learning organization, Gherardi responded in a thoughtprovoking way by discussing how cognitive theories, change management, knowledge management and other organizational and computer science theories focused mainly on these concepts during the 1990s. The concept of organizational learning is the result of divergences between two bodies of literature - organizational learning and learning organization - in the 1980s and 1990s, and the continued development in the field.

Indeed, the following definition appears in her earlier contributions:

Organizational learning is a metaphor that matches two concepts - learning and organization and enables exploration of the organization as if it were a subject which learns, deals with knowledge, reflects on experiences, and is endowed with a stock of knowledge, skills, and expertise (Gherardi, 2001). 
She viewed organizational learning as a metaphor revealing the importance of language and symbols in the formulation of theory when investigating organization and learning.

Gherardi then states that:

[...] the representation of the learning organization may stand as a valid theoretical alternative to the rational organization because it replaces the classical concept of the organization that acts according to the principles of rational choice with that of the organization which acts according to principles of experimentation, of trial and error, of success and failure, of discovery and invention (Gherardi, 2001).

\section{What was the basis for your original study of learning organization theory?}

Here, Gherardi recalled the scientific context in which she began to study and write on organizational learning, and how it came into her research design. She states:

In the 1990s, I was writing about learning in organizations mainly in Italian and I was collaborating with Duccio Demetrio, who is a well-known educationalist, and Donata Fabbri, an Italian cultural psychologist working in Genève.

The team was made up of experts with different disciplinary backgrounds and Gherardi became acquainted with the fact that "learning" is multiple, ambiguous and culturally dependent (Demetrio et al., 1994). In that book, entitled in English Learning in Organizations, she contributed a chapter on learning in decision-making, describing the discursive construction of a decision-making process. Gherardi states that:

I was proposing to consider organizational learning as a metaphor juxtaposing two terms organization and learning - to explore a system of representation. In other words, the metaphor of organizational learning enables us to look at organizations as if they were a system that learns. Accordingly, to the many ways of conceiving what an organization "is" correspond many ways of defining what can count as "learning".

Gherardi has taken part in the wider intellectual milieu that introduced new epistemological contributions with the aim of overcoming the limits of the positivist and rationalist understanding of organizational studies. She continued, "In the 1990s, organization studies went through in-depth changes thanks to the movement of the cultural and symbolic approach to organization."

An example of innovation in the field was the concept of metaphors introduced by Morgan (1986) who argued that organization cannot be understood or explained by one theory alone, but only from several different perspectives called metaphors. Metaphors are the basis of organizational reflection and organizational action. Overcoming the simple mechanistic models, Morgan explored organizations as organisms and organizations as cultures, focusing on the self-creating processes of the organization.

At that time, almost all social disciplines were looking at the metaphorical grounding of their theories in the same way that "organizational culture" was used to ground a cultural approach to organization, and Gherardi explained:

I proposed to conceive of "organizational learning" as a way of conducting an inquiry on whatever an organization "does" with knowledge: acquiring, transferring, storing, transforming, creating and packaging. The boundaries between learning and knowing were not relevant and, in fact, I always write about "learning and knowing" without stressing a substantial difference.

In 1995, Gherardi wrote her first English article on the subject in the International Encyclopedia of Business and Management and provided the definition of organizational learning as a metaphor based on the two concepts of "learning" and "organization", thus giving a sufficiently
Social science interview 
abstract view on a very complex domain of study (Gherardi, 1995). This was quite different from the long debate scholars had had, and are still having, about what organizational learning is, who learns within an organization, when learning takes place, etc. In her opinion, the discussion on these topics has often been very positivistic and mechanistic.

Gherardi stated:

I was arguing that the study of organizations as if they were systems which learn could be of assistance in the design of organizations that learn. The learning organization may in fact stand as a valid theoretical alternative to the rational organization because it replaces the classical concept of the organization which acts according to the principles of rational choice with that of the organization which acts according to principles of experimentation, of trial and error, of success and failure, of discovery and invention. Unfortunately, the metaphor of "the learning organization" in those years underwent a genetic mutation and was taken in a prescriptive manner, linking it to an identity concern.

Discussions ensured to conflate learning and knowing, order and disorder, organization and organizing. Knowing took the place of knowledge, the action of learning and organizing became more relevant in organization, and practice-based findings gained a relevant role in the analysis of a collective knowledgeable doing situated in working actions.

\section{From your earliest definitions of learning organization, how has your definition evolved over time?}

Gherardi did not really want to answer at this question mainly because in her studies she attempts to avoid the label "learning organization", as she has studied the key divergences in the real nature of organizational learning. She explained:

$[\ldots]$ in the title "Organizational learning and learning organization: diverging communities of practice?" there was a question about how the two communities were going to diverge and indeed how much they already had (Easterby-Smith et al., 1998).

With her colleagues, Gherardi identified four sets of issues which reflect opposing assumptions regarding: the purpose of the organizational learning (teleology), the very essence of organizational learning (ontology), the research methodologies for researching and improving the ability of the organization to learn (epistemology) and the effectiveness of organizational learning intervention (technology).

Gherardi said:

Nevertheless, in my opinion, the reason for taking different roads and for looking at each other with suspicion lay in the ideological character attributed to the label "learning organization" as a marker of organizational identity and the underlying construction of power [...].

\section{What are your thoughts on the multiple definitions of the learning organization?} In recent studies, authors are still debating whether learning organization is still alive. Pedler et al. (1991) and Pedler and Burgoyne (2017) argued that learning organization is still alive but living under different names. For instance, in some academic and practitioner circles, learning organization lead to knowledge management and was then reinvented as dynamic capability with a different theoretical basis.

Investigating the various contributions on learning organization, various definitions and perspectives can be identified. In the 1980-1990s, discussions abounded on the very essence, purpose, effectiveness and the methodologies of learning organization. These approaches focused on discovering the very nature of learning organization and knowledge, often creating strong confrontations among epistemologies, ontologies and approaches. The duality between knowledge as an object (explicit and crystalized) and knowledge as the 
action of knowing (subjective, dynamic, embedded in the body of people and their social relations) also arose. The pioneering work of March and Simon (1958), Argyris and Schon (1974) and Weick (1991) stressed the duality between individual learning (cognitions, interpretations, mental maps) and knowledge that can be institutionalized and incorporated into new organizational situations such as procedures, practices, rules, goals and values. One of the main problems of these approaches derives from the fact that traditional psychological models of learning have been uncritically transferred to the study of learning organization. Recalling a previous work (Gherardi, 2001), Gherardi explained, "The utopia of unifying and integrating the field that characterized the 1980s failed in the 1990s and gave way to the encouragement of the existing diversity of perspectives."

In recent years, new managerial practices such as knowledge management, dynamic capabilities, change management - triggered often by technologies - really affected the thoughts around learning organization. Gherardi also added, "What they have in common is the managerial interest in bringing knowledge under control at the service of production or innovation."

In other studies, it emerged that both managers and technicians prefer to deal with a normative approach because it allows an easier control of fixed patterns of knowledge, development of centralized information and the management of knowledge (Bonifacio et al., 2002). In this case learning organization can manage knowledge by relying on available input and providing solutions, such as artefacts used by members to interact and coordinate. Learning is visible only when the set of information and knowledge change and new solutions are undertaken.

To overcome this duality, a new meta-ontological approach should be introduced in the field of learning organization studies. The advent of practice-based studies, which provide an innovative lens of analysis, offer a broader perspective on the organizational phenomenon as it takes into consideration aspects such as aesthetics, embodiment and socio-materiality, and influences research methodologies.

\section{How did her framework evolve?}

Gherardi states:

In practice-based theorizing, different traditions of studying learning merge without losing their identity: situated learning theory offers the concept of community of practice, actor-network theory brings the idea of knowledge grounded in materiality, activity theory offers a pragmatic theory of action, and the ethnographic study of knowledgeable communities brings a research method which is anti-individualistic.

On the one hand, practices constitute an institutionalized ordering of the flow of organizational relations, sustained by material and social relations. On the other, they can be temporary and unstable when answering the problem of dealing with uncertainty and innovation.

As a consequence, a very useful lens to examine Learning Organization is to focus on practices as the place in which actions, coordination and change are "becoming" as a social construction. In this case, the concept of normativity can be embedded in the concept of becoming institutionalized, commonly shared and socially accepted.

In her last work, the second and renewed edition of How to Conduct a Practice-Based Study: Problems and Methods, Gherardi emphasizes her latest developments in theories and proposes research based on an onto-epistemology of what constitutes a practice. While she explains how to develop practice-based studies, she also clarifies her viewpoint on these 
particular studies by outlining the link to socio-technical studies, actor network theory and relational epistemologies.

\section{Conclusion}

Our interview with Professor Silvia Gherardi has been very challenging and thoughtprovoking. By discussing a common definition on learning organization, the innovative contribution of Professor Gherardi emerged, namely, how does organizing really occur and how does this concept constitute the building block of the practice-based studies?

Thanks to Gherardi's contributions and by adopting practice as the basic unit of analysis of organizing, researchers can study work in a contextual rationality that emerges from the interconnection between actors, materiality, discourses and knowledge. Moreover, through ethno-methodological approaches, practical knowledge and situated activity can be identified and studied in depth.

Finally, the epistemology of practice enables the analysis of the generation and development (called by Gherardi as becoming) of a practice and the pre-ordered sociomaterial contexts in which it develops. This is of particular importance when a technology is adopted in organization because it enables researchers or practitioners to better understand the social impacts of the adoption of any technological solution.

Both researchers and practitioners can take strong advantage of Gherardi contributions, as they can better understand most of the phenomena that managerial approaches and model are not able to focus on.

\section{References}

Argyris, C. and Schon, D.A. (1974), Theory in Practice: Increasing Professional Effectiveness, JosseyBass.

Bonifacio, M., Bouquet, P. and Cuel, R. (2002), "Knowledge nodes: the building blocks of a distributed approach to knowledge management", Journal of Universal Computer Science, Vol. 8 No. 6, pp. 652-661.

Bruni, A. and Gherardi, S. (2007), "Studiare le pratiche lavorative", Il mulino.

Demetrio, D. Fabbri, D. and Gherardi, S. (1994), "Apprendere nelle organizzazioni, a cura di duccio demetrio", Carocci, Roma.

Easterby-Smith, M., Snell, R. and Gherardi, S. (1998), "Organizational learning: diverging communities of practice?”, Management Learning, Vol. 29 No. 3, pp. 259-272.

Gherardi, S. (1995), "Organizational learning”, in Warner, M. (Ed.), International Encyclopedia of Business and Management, Routledge, London, pp. 3934-3942.

Gherardi, S. (2000), "Practice-based theorizing on learning and knowing in organizations", Organization, Vol. 7 No. 2, pp. 211:223.

Gherardi, S. (2001), "The learning organization", in Smelser, N.J. and Baltes, P.B. (Eds) (2001), International Encyclopedia of the Social and Behavioral Sciences, Elsevier, Amsterdam, Vol. 11, ISBN: 0-08-043076-7.

Gherardi, S. (2006), Organizational Knowledge: The Texture of Workplace Learning, John Wiley and Sons.

Gherardi, S. (2009), "Introduction: the critical power of the `practice lens", Management Learning, Vol. 40 No. 2, pp. 115-128, available at: https://doi.org/10.1177/1350507608101225

Gherardi, S. (2012), How to Conduct a Practice-Based Study: Problems and Methods, Edward Elgar Publishing. 
Gherardi, S. (2019), How to Conduct a Practice-Based Study: Problems and Methods, Edward Elgar Publishing.

March, J.C. and Simon, H.A. (1958), Organizations, Wiley, New York, NY.

Morgan, G. (1986), Images of Organization, Sage, Beverly Hills.

Pedler, M. and Burgoyne, J.G. (2017), "Is the learning organisation still alive?", The Learning Organization, Vol. 24 No. 2.

Pedler, M., Burgoyne, J.G. and Boydell, T. (1991), The Learning Company, McGraw-Hill, Maidenhead.

Reese, S. (2020), “Taking the learning organization mainstream and beyond the organizational level: an interview with Peter Senge", The Learning Organization, Vol. 27 No. 1, available at: https://doi. org/10.1108/TLO-09-2019-0136

Sidani, Y. and Reese, S. (2018a), “A journey of collaborative learning organization research: interview with Victoria Marsick and Karen Watkins”, The Learning Organization, Vol. 25 No. 3, pp. 199-209, available at: https://doi.org/10.1108/TLO-01-2018-0015

Sidani, Y. and Reese, S. (2018b), "A view of the learning organization from a corporate governance perspective: interview with Bob Garratt”, The Learning Organization, Vol. 25 No. 6, pp. 434-442, available at: https://doi.org/10.1108/TLO-07-2018-0122

Weick, K.E. (1991), “The nontraditional quality of organizational learning”, Organization Science, Vol. 2 No. 1, pp. 116-124.

\section{Corresponding author}

Roberta Cuel can be contacted at: roberta.cuel@unitn.it

Social science interview 